\title{
Microstructure, dielectric and piezoelectric properties of lead-free $\mathrm{Bi}_{0.5} \mathrm{Na}_{0.5} \mathrm{TiO}_{3}-\mathrm{Bi}_{0.5} \mathrm{~K}_{0.5} \mathrm{TiO}_{3}-\mathrm{BiMnO}_{3}$ ceramics
}

\author{
HUABIN YANG*, XU SHAN, CHANGRONG ZHOU, QIN ZHOU, WEIZHOU LI ${ }^{\dagger}$ \\ and JUN CHENG \\ School of Materials Science and Engineering, Guilin University of Electronic Technology, Guilin, Guangxi 541004, \\ People's Republic of China \\ ${ }^{\dagger}$ School of Materials Science and Engineering, Guangxi University, Nanning, Guangxi 530004, \\ People's Republic of China
}

MS received 30 August 2011

\begin{abstract}
To improve the piezoelectric properties of $\mathrm{Bi}_{0.5} \mathrm{Na}_{0.5} \mathrm{TiO}_{3}$-based ceramics, a new perovskite-type leadfree piezoelectric $(1-x-y) \mathrm{Bi}_{0.5} \mathrm{Na}_{0.5} \mathrm{TiO}_{3}-x \mathrm{Bi}_{0.5} \mathrm{~K}_{0.5} \mathrm{TiO}_{3}-y \mathrm{BiMnO}_{3}$ system has been fabricated by a conventional solid-state reaction method and their microstructure, dielectric and piezoelectric properties have been investigated. The results of X-ray diffraction (XRD) analysis reveal that the addition of small amounts of $\mathrm{BiMnO}_{3}$ did not cause a remarkable change in crystal structure, but resulted in an evident evolution in microstructure. An obvious secondary phase was observed in samples with high $\mathrm{Bi}_{0.5} \mathrm{~K}_{0.5} \mathrm{TiO}_{3}$ content. It is found from dielectric constant curves that low-temperature hump disappeared with increasing $y$ and it appeared again with increasing $x$. The piezoelectric properties significantly increase with increasing $\mathrm{Bi}_{0.5} \mathrm{~K}_{0.5} \mathrm{TiO}_{3}$ and $\mathrm{BiMnO}_{3}$ content. The piezoelectric constant and electromechanical coupling factor attain maximum values of $d_{33}=182 \mathrm{pC} / \mathrm{N}$ at $x=0 \cdot 21(y=0.01)$ and $k_{\mathrm{p}}=0.333$ at $x=0.18(y=0.01)$, respectively.
\end{abstract}

Keywords. Piezoelectricity; perovskites; electroceramic; electrical properties.

\section{Introduction}

Lead zirconate titanate (PZT) and lead-based ceramics have outstanding piezoelectric properties and have been widely used as piezoelectric devices. However, since $\mathrm{PbO}$ is toxic and evaporates during the sintering process, PZT ceramics pose serious environmental problems. Therefore, extensive research has been directed on lead-free piezoelectric materials to replace $\mathrm{Pb}$-based ceramics. Research work is focused on lead-free systems with perovskite-type structure compositions based on bismuth sodium titanate $\left(\mathrm{Bi}_{0.5} \mathrm{Na}_{0.5}\right) \mathrm{TiO}_{3}$ (BNT) and $\mathrm{K}_{0.5} \mathrm{Na}_{0.5} \mathrm{NbO}_{3}$ (KNN), which are especially promising candidates (Sawada et al 2003; Suzuki et al 2003; Saito et al 2004; Jarupoom et al 2008; Wu et al 2008). However, NNK ceramics are difficult to sinter by the conventional solid-state method and decompose when exposed to moisture (Du et al 2008). Complicated procedures are required for fabricating dense, high quality alkali niobate ceramics which call for special forming methods (i.e. cold isostatic pressing, hot pressing) and sintering methods (e.g. spark plasma sintering) (Jaeger and Egerton 1962; Wang et al 2002; Li et al 2006). Those complicated procedures entail high cost and limit the popularization of the materials in becoming a commercial product.

\footnotetext{
*Author for correspondence (yhb_letters@163.com)
}

Bismuth-based lead-free perovskite is based on BNT, which is considered one of the good candidates for leadfree piezoelectric ceramics because of its strong ferroelectric properties (Smolenski and Aganovskaya 1960). However, as-reported by many scientists (Wang et al 2003; Yang et al 2008; Zhou and Liu 2008), BNT presents interesting piezoelectric properties, but the major drawbacks are (i) a quite high coercive field, (ii) high conductivity, which causes difficulties in the poling process and (iii) quite low piezoelectric properties of pure BNT. These problems were improved by forming solid solutions with $\mathrm{BaTiO}_{3}$ (Chu et al 2002), $\mathrm{K}_{0.5} \mathrm{Bi}_{0.5} \mathrm{TiO}_{3}$ (Yang et al 2008), $\mathrm{NaNbO}_{3}$ (Ishii et al 2001), and so on. Based on earlier studies, $(1-x) \mathrm{Bi}_{0.5} \mathrm{Na}_{0.5} \mathrm{TiO}_{3}-x \mathrm{Bi}_{0.5} \mathrm{~K}_{0.5} \mathrm{TiO}_{3}(\mathrm{BNT}-\mathrm{BKT})$ system has good properties and attracts considerable attention because of the existence of rhombohedral-tetragonal morphotropic phase boundary (MPB) near $x=0.18$ (Elkechai et al 1996). Therefore, BNT-BKT was chosen as a basic chemical formula in our study. On the other hand, most of the piezoelectric properties were improved in ternary system compared with the binary (Wang et al 2004). Generally, Bi-containing perovskite solid solutions show high piezoelectric and ferroelectric responses for $\mathrm{Bi}^{3+}$ and is isoelectronic with $\mathrm{Pb}^{2+}$ and show a valence electron configuration of $6 s^{2} 6 p^{0}$ (Du et al 2008). On the other hand, it has been reported that large ferroelectricity of BNT-based solid solutions is attributed to $\left(\mathrm{Bi}_{1 / 2} \mathrm{Na}_{15}\right)^{2+}$ ions, especially $\mathrm{Bi}^{3+}$ ions, on the A-sites of $\mathrm{ABO}_{3}$ perovskite structure. As a candidate 
for the BNT-based solid solutions, without decreasing the amount of $\mathrm{Bi}^{3+}$ ions and keeping an electrical neutrality, new $\mathrm{Bi}$-based perovskite type lead-free piezoelectric ceramics $(1-x-y) \mathrm{Bi}_{0.5} \mathrm{Na}_{0.5} \mathrm{TiO}_{3}-x \mathrm{Bi}_{0.5} \mathrm{~K}_{0.5} \mathrm{TiO}_{3}-y \mathrm{BiMeO}_{3}$ (Me: trivalent metals such as $\mathrm{Fe}, \mathrm{Cr}, \mathrm{Co}, \mathrm{Al}$ and $\mathrm{Mn}$ ) have been developed by our group. Early studies on bismuthbased perovskite-structured $\mathrm{BiMeO}_{3}-\mathrm{PbTiO}_{3}$ solid solutions were focused on compounds containing transition-metal Me ions such as $\mathrm{Mn}^{3+}$ and $\mathrm{Fe}^{3+}$ (Fedulov et al 1962; Bokov et al 1969). These materials show very high Curie temperature. Following these, a new ternary BNT-based leadfree ceramic, $(1-x-y) \mathrm{Bi}_{0.5} \mathrm{Na}_{0.5} \mathrm{TiO}_{3}-x \mathrm{Bi}_{0.5} \mathrm{~K}_{0.5} \mathrm{TiO}_{3}-$ $y \mathrm{BiMnO}_{3}$ (abbreviated as $(1-x-y)$ BNT- $x$ BKT $\left.-y \mathrm{BM}\right)$, was prepared by a conventional solid-state sintering process, and its microstructure and electrical properties were studied systematically.

\section{Experimental}

A conventional ceramics technique was used to prepare $(1-x-y)$ BNT $-x$ BKT $-y$ BM ceramics $(x=0 \cdot 12,0 \cdot 15$, $0.18,0.21$ and $0.24 ; y=0,0.01,0.015,0.02$ and 0.025 ). Reagent grade oxide or carbonate powders of $\mathrm{Bi}_{2} \mathrm{O}_{3}, \mathrm{TiO}_{2}$, $\mathrm{MnCO}_{3}, \mathrm{~K}_{2} \mathrm{CO}_{3}$ and $\mathrm{Na}_{2} \mathrm{CO}_{3}$ were used as starting materials. The powders were wet ball-milled with alcohol as media for $12 \mathrm{~h}$ and calcined at $800-900{ }^{\circ} \mathrm{C}$ for $2 \mathrm{~h}$ at a heating rate of $150{ }^{\circ} \mathrm{C} / \mathrm{h}$. After calcination, the mixture was wet ballmilled for $24 \mathrm{~h}$, dried and granulated with $5 \mathrm{wt} \%$ PVA as a binder. The granulated powders were pressed into discs with diameter of $18 \mathrm{~mm}$ and thickness of $1.2 \mathrm{~mm}$ under an uniaxial pressure of $100 \mathrm{MPa}$. The compacted discs were sintered at $1150-1170{ }^{\circ} \mathrm{C}$ for $2 \mathrm{~h}$ at a heating rate of $200{ }^{\circ} \mathrm{C} / \mathrm{h}$ and then furnace cooled down to room temperature very slowly in $24 \mathrm{~h}$. Silver paste was fired on both faces of the discs at $650{ }^{\circ} \mathrm{C}$ as electrodes. The specimens for measurement of piezoelectric properties were poled in silicone oil at 40 $50{ }^{\circ} \mathrm{C}$ under $3-4 \mathrm{kV} / \mathrm{mm}$ for $15 \mathrm{~min}$. After $24 \mathrm{~h}$, piezoelectric properties were measured according to IEEE standard.

The crystalline phase of sintered ceramics was identified by X-ray diffractometer (Bruker D8-Advance) with $\mathrm{CuK} \alpha$ radiation $(\lambda=1.5418 \AA)$ and graphite monochromator. The microstructure of sintered samples was observed by a scanning electron microscope (JSM-5610LV). Piezoelectric and dielectric properties were measured using an impedance analyser (Agilent 4294A). Piezoelectric constant $d_{33}$ was measured by means of a quasi-static $d_{33}$ meter (ZJ-3A, China) based on the Berlincourt method at $110 \mathrm{~Hz}$.

\section{Results and discussion}

The X-ray diffraction (XRD) patterns of $(1-x-y)$ BNT$x$ BKT $-y$ BM ceramics with $x=0 \cdot 12-0.24$ and $y=0-0.025$ are shown in figure 1 . It can be seen that all the patterns look similar and the XRD peaks do not change evidently with increasing $x$ and $y$ and all the samples with $x \leq 0.21$ crystallize in a pure perovskite phase, indicating the formation of
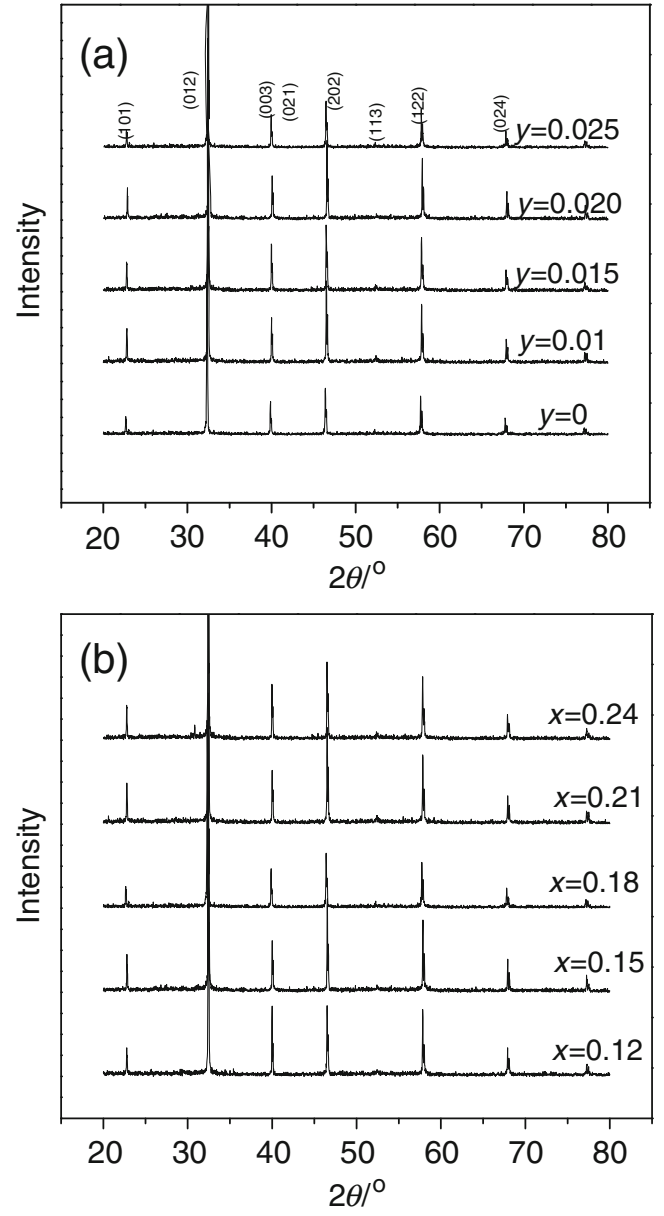

Figure 1. XRD pattern of $(1-x-y) \mathrm{BNT}-x \mathrm{BKT}-y \mathrm{BM}$ ceramics: (a) $x=0.18$ and (b) $y=0.01$.

BNT-BKT-BM solid solution. However, some weak peaks were observed for $x=0.24$ at $2 \theta=31-33^{\circ}$, which arise from the formation of a small amount of secondary phase.

The scanning electron microscopy (SEM) micrographs of the $(1-x-y)$ BNT $-x$ BKT $-y$ BM ceramics are shown in figure 2. The sample of pure BNT-BKT ceramics has a monomodal microstructure, consisting of small grains $\sim 1.5 \mu \mathrm{m}$ in radius and many distinct pores in the grain boundary. The sample with $0.02 \mathrm{BiMnO}_{3}$ addition consists of cube-shaped grains $\sim 3.0 \mu \mathrm{m}$ in radius with sharp edges and corner (figure 2(c)). The sample with $0.025 \mathrm{BiMnO}_{3}$ addition also consists of cubic grains $\sim 3.3 \mu \mathrm{m}$ in radius but with some rounded edges and corners (figure 2(d)) and has faceted grain boundaries. It is easily observed that the grain size of the samples increases with increasing amount of $\mathrm{BiMnO}_{3}$, which indicates that $\mathrm{BiMnO}_{3}$ is acting as a sintering aid in $(1-x-y)$ BNT $-x$ BKT $-y$ BM ceramics. In addition, the average grain size decreases with increasing content of BKT. The density, theoretical density and density ratio of $(1-x-y) \mathrm{BNT}-x \mathrm{BKT}-y \mathrm{BM}$ ceramics are shown in table 1 . It can be seen from table 1 that density and density ratio increase obviously with increasing the content of $\mathrm{BiMnO}_{3}$, and density and density ratio increase slowly with increasing the content of BKT. 

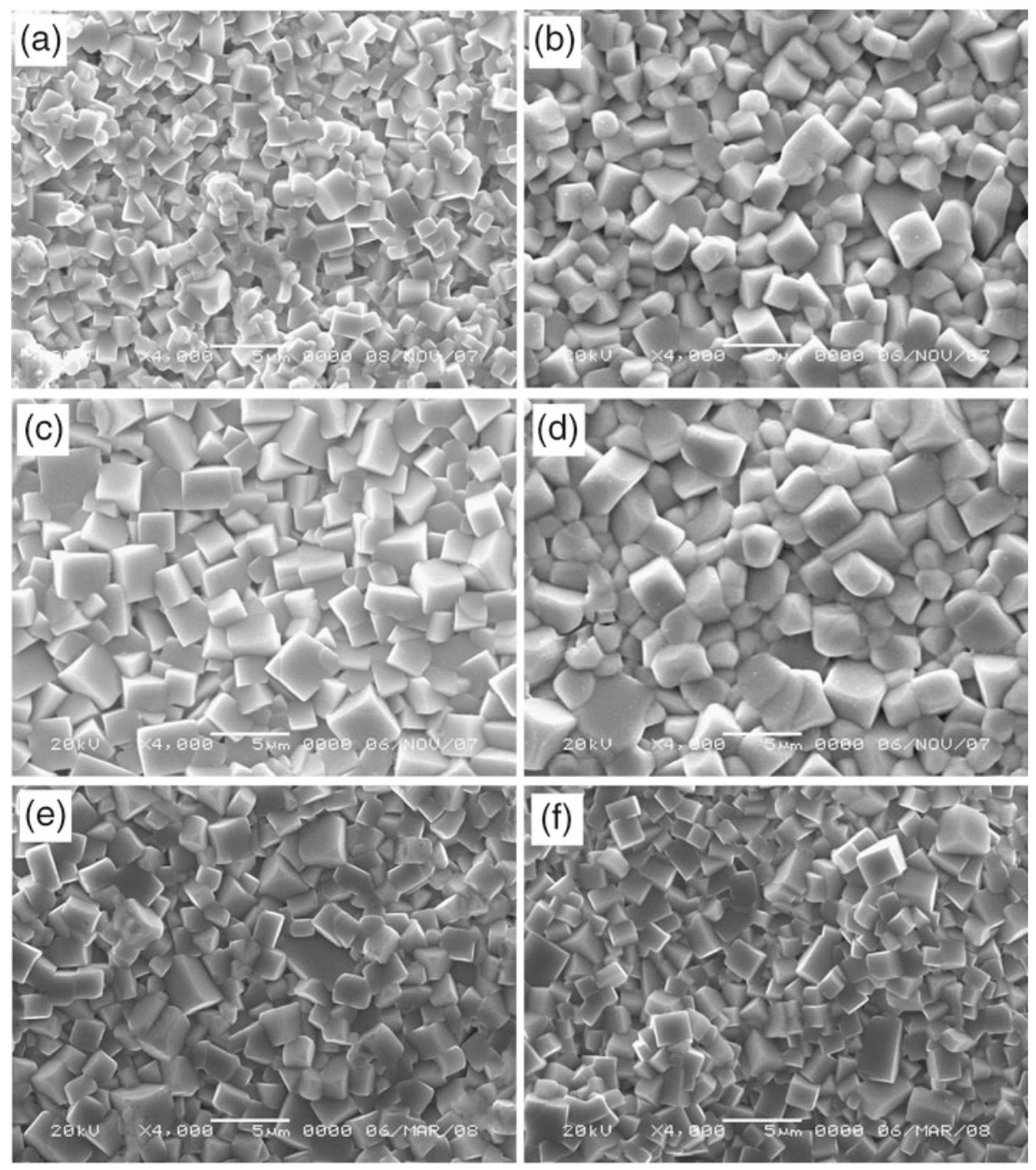

Figure 2. SEM images of $(1-x-y) \mathrm{BNT}-x \mathrm{BKT}-y \mathrm{BM}$ ceramics: (a) $x=0 \cdot 18, y=0$; (b) $x=0.18, y=0.01$; (c) $x=0.18, y=0.02$; (d) $x=0.18, y=0.025$; (e) $x=0.21, y=$ $0 \cdot 01$ and (f) $x=0.24, y=0 \cdot 01$.

Table 1. Density, theoretical density and density ratio of $(1-x-y) \mathrm{BNT}-x \mathrm{BKT}-y \mathrm{BM}$ ceramics.

\begin{tabular}{lccc}
\hline$x, y$ & $\rho_{\text {th }}\left(\mathrm{g} / \mathrm{cm}^{3}\right)$ & $\rho\left(\mathrm{g} / \mathrm{cm}^{3}\right)$ & $\rho_{\text {re }}(\%)$ \\
\hline$x=0 \cdot 18, y=0$ & 5.990 & 5.632 & 94.0 \\
$x=0 \cdot 18, y=0 \cdot 01$ & 5.992 & 5.725 & 95.5 \\
$x=0 \cdot 18, y=0.015$ & 5.992 & 5.732 & 95.7 \\
$x=0 \cdot 18, y=0.02$ & 5.993 & 5.740 & 95.8 \\
$x=0 \cdot 18, y=0.025$ & 5.996 & 5.765 & $96 \cdot 1$ \\
$x=0 \cdot 12, y=0.01$ & 5.986 & 5.620 & 93.9 \\
$x=0 \cdot 15, y=0.01$ & 5.986 & 5.625 & 94.0 \\
$x=0 \cdot 21, y=0.01$ & 5.991 & 5.635 & 94.1 \\
$x=0 \cdot 24, y=0.01$ & 5.992 & 5.636 & 94.1 \\
\hline
\end{tabular}

Figure 3 reveals temperature dependence of dielectric constant, $\varepsilon_{\mathrm{r}}$ for the poled $(1-x-y) \mathrm{BNT}-x \mathrm{BKT}-y \mathrm{BM}$ samples. For the specimen with $x=0 \cdot 18$ and $y=0$, there are two dielectric anomalies in the measuring temperature range, a weak hump and abroad dielectric peak. This behaviour is rather analogous to those previously observed in BNT-BKT ceramics ( $\mathrm{Li}$ et al 2005), with the two dielectric anomalies being referable to a ferroelectric-antiferroelectric transition and a subsequent transition to para-electric state, respectively. The lines in figure 3(a) indicate two characteristic temperatures. The temperature corresponding to ferroelectric-antiferroelectric transition is termed as depolarization temperature $\left(T_{\mathrm{d}}\right)$ because the specimen is basically depolarized and loses piezoelectric activity above this temperature (Zhang et al 2007). The temperature at which the peak value of dielectric constant occurs is named as maximum temperature $\left(T_{\max }\right)$. The diffuse phase transition behaviour of the specimen is in agreement with the nature of the BNT-BKT as a relaxor ferroelectric. The mechanism of diffuse phase transition in complex perovskite-type relaxor ferroelectrics has been elucidated from different viewpoints (Smolenski and Agranovskaya 1958; Cross 1987). We 

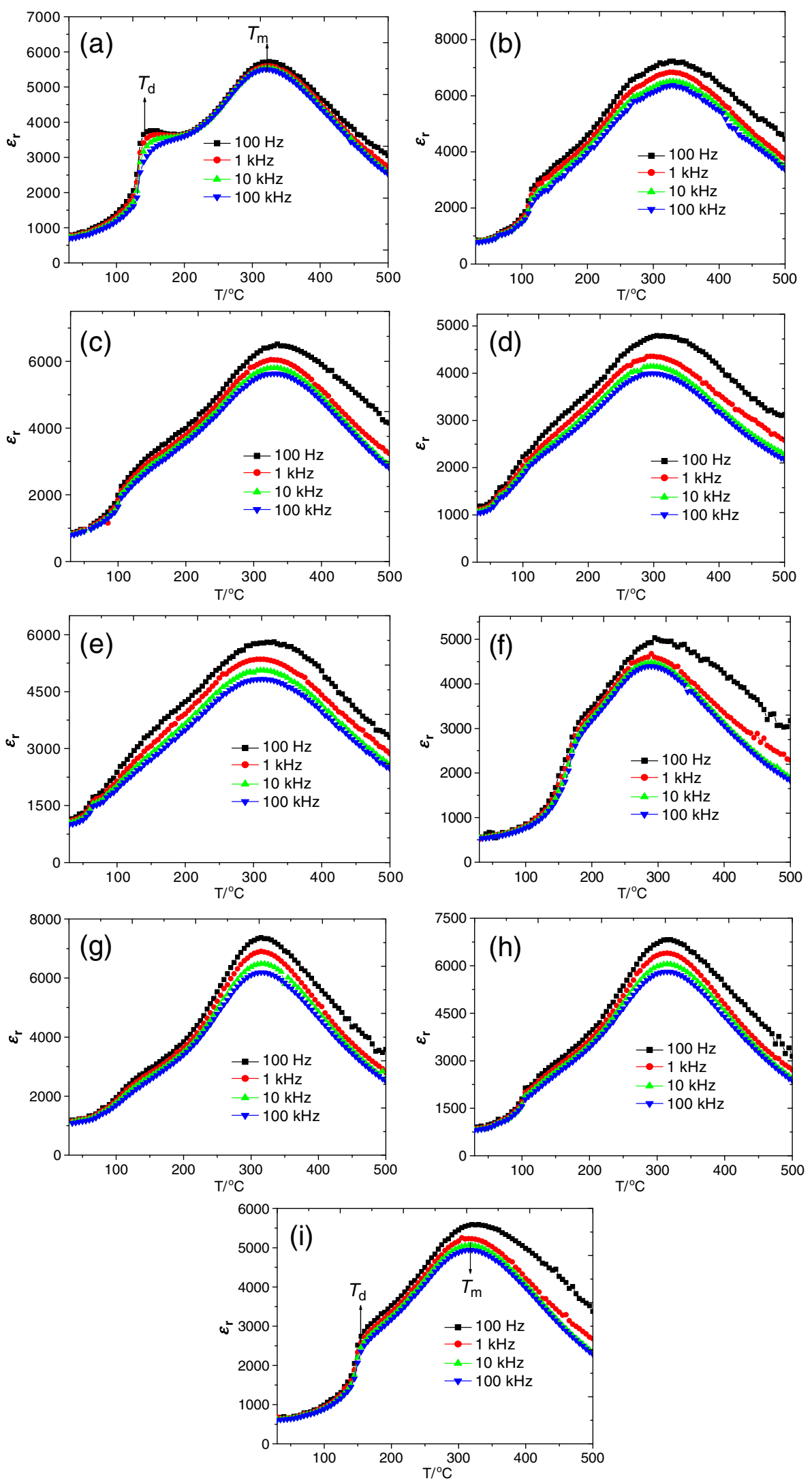

Figure 3. Temperature dependences of $\varepsilon_{\mathrm{r}}$ for poled $(1-x-y)$ BNT- $x$ BKT- $y$ BM samples: (a) $x=0.18, y=0$; (b) $x=0.18, y=0.01$; (c) $x=0.18, y=0.015$; (d) $x=0.18, y=0.02$; (e) $x=0.18, y=0.025$; (f) $x=0.12, y=0.01$; (g) $x=0.15, y=0.01$; (h) $x=0.21, y=0.01$ and (i) $x=0 \cdot 24, y=0 \cdot 01$. 
have considered that this behaviour is closely related to the coexistence of complex ions $\left(\mathrm{Na}^{+}, \mathrm{Bi}^{3+}\right.$ and $\left.\mathrm{K}^{+}\right)$, which possess similar radii but different charges and electron configurations, at an equivalent crystallographic site. It was also found from figure 3 that the low-temperature hump in dielectric constant curve of $(1-x-y)$ BNT $-x$ BKT$y \mathrm{BM}$ ceramics disappeared slowly with increasing $y$ and appeared again with increasing $x$. A similar phenomenon was observed in $\left(\mathrm{Na}_{0.5} \mathrm{Bi}_{0.5}\right)_{0.94} \mathrm{Ba}_{0.06} \mathrm{TiO}_{3}$ ceramics with a small amount of $\mathrm{Co}_{2} \mathrm{O}_{3}$ added and $\left(\mathrm{Na}_{0.5} \mathrm{Bi}_{0.5}\right)_{0.93} \mathrm{Ba}_{0.07} \mathrm{TiO}_{3}$ ceramics with a small amount of $\mathrm{CoO}$ added (Li et al 2004; $\mathrm{Xu}$ et al 2008). This can be explained in terms of the incorporation of Co into the lattice and generation of oxygen vacancies. Successive ferroelectric-antiferroelectric-para-electric transition with increasing temperature had previously been observed in varieties of lead-based complex perovskite compounds and BNT-based compositions (Yasuda and Konda 1993; Lee et al 2004). The intermediate antiferroelectric state has been strictly classified as a normal antiferroelectric state and can be explained in light of a subtle modulation of spontaneous polarization (Randall et al 1989; Randall and Bhalla 1990). The weak hump in the dielectric constant curve can be regarded as a response to such incommensurate modulation. Based upon the transmission electron microscopy (TEM) observation, it has been revealed that there is a direct interaction between ferroelectric domains and the incommensurate modulation, with ferroelectric domain walls acting as barriers (Randall and Bhalla 1990). According to Shannon's effective ionic radii with a coordination number of $6, \mathrm{Mn}^{3+}$ has a radius of $0.65 \AA$, which is close to that of $\mathrm{Ti}^{4+}(0.61 \AA)$ (Shannon 1976). Therefore, $\mathrm{Mn}^{3+}$ can enter into the six-fold coordinated $\mathrm{B}$ site of the perovskite structure to substitute for $\mathrm{Ti}^{4+}$ because of radius matching. Due to a lower valence state compared with $\mathrm{Ti}^{4+}$, the incorporation of $\mathrm{Mn}^{3+}$ into the octahedral site of the structure produced excess negative charges. To maintain overall electrical neutrality, oxygen vacancies were created for compensation purposes. As is well known, oxygen vacancies in perovskite-type ferroelectrics have a clamping effect on the motion of domain walls. Then, it is plausible that the clamping effect associated with the appearance of oxygen vacancies caused by adding $\mathrm{BiMnO}_{3}$ could dynamically suppress the degree of modulating spontaneous polarization. This is believed to be the main reason for the disappearance of the weak hump in the dielectric constant curves of the $(1-x-y) \mathrm{BNT}-x \mathrm{BKT}-y \mathrm{BM}$ ceramics.

Piezoelectric constant $d_{33}$ and the planar electromechanical coupling factor, $k_{\mathrm{p}}$ in $(1-x-y) \mathrm{BNT}-x \mathrm{BKT}-$ $y \mathrm{BM}$ system were measured and are shown in figure 4 . It reveals that the evolutions of these properties as function of BKT and $\mathrm{BiMnO}_{3}$ amount in $(1-x-y) \mathrm{BNT}-x \mathrm{BKT}-y \mathrm{BM}$ ceramics are similar. Both $d_{33}$ and $k_{\mathrm{p}}$, first enhance and then decrease with increasing $\mathrm{BKT}$ and $\mathrm{BiMnO}_{3}$ ratio. $d_{33}$ reaches maximum value of $182 \mathrm{pC} / \mathrm{N}$ at $x=0.21(y=0.01)$, and $k_{\mathrm{p}}$ reaches maximum value of 0.333 at $x=0.18(y=0 \cdot 01)$, respectively.
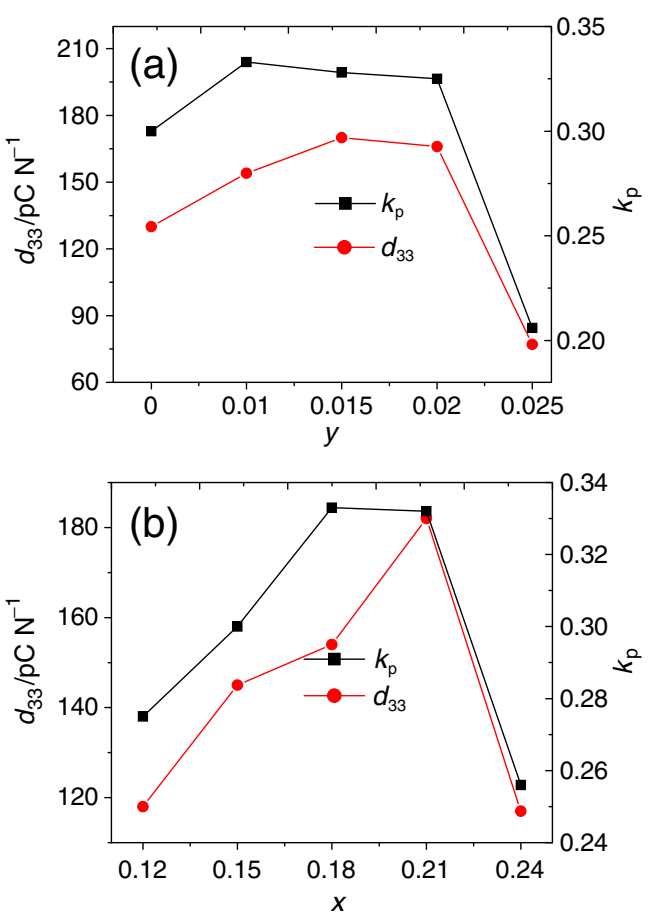

Figure 4. Piezoelectric constant, $d_{33}$ and planar electromechanical coupling factor $k_{\mathrm{p}}$ of $(1-x-y) \mathrm{BNT}-x \mathrm{BKT}-y \mathrm{BM}$ ceramics: (a) $x=0.18$ and (b) $y=0.01$.

Piezoelectric response of ceramics may be affected by many factors, including crystal structure and microstructure of ceramics, presence of impurities, dopants, defects and local variation in the composition of ceramics (Jaffe et al 1971; Zhang et al 1988). Piezoelectric properties are strongly dependent on the degree of polarization as set by the poling process. Polarization depends on domain wall mobility, which in turn depends on domain size and grain size. Many investigations reveal that piezoelectric properties increase with increasing grain size, which is called size-effect (Randall et al 1998). Moreover, bismuth lies next to lead in the periodic table and its atomic weight is as large as that of lead. Further, electronic configuration of $\mathrm{Bi}^{3+}$ is identical to that of $\mathrm{Pb}^{2+}$. Therefore, it is assumed that the large ferroelectricity of BNT-based solid solutions is attributed to $\left(\mathrm{Bi}_{0.5} \mathrm{Na}_{0.5}\right)^{2+}$ ions, especially $\mathrm{Bi}^{3+}$ ions, in the A-site of $\mathrm{ABO}_{3}$ perovskite structure (Nagata and Takenaka 1997, 1998). On the other hand, the clamping effect caused by oxygen vacancies can restrain the motion of ferroelectric domains, and thus reduce piezoelectric properties. Variation of $d_{33}$ and $k_{\mathrm{p}}$ for $(1-x-y) \mathrm{BNT}-x \mathrm{BKT}-y \mathrm{BM}$ ceramics can be roughly understood in relation to the co-contribution of bismuth content effect, size-effect and oxygen vacancy effect. From figure 4, one can suggest that the bismuth content and size-effect seem to be the main contributing factors at relatively low $\mathrm{BiMnO}_{3}$ amounts, while oxygen vacancy effect appears to be dominant at relatively high $\mathrm{BiMnO}_{3}$ amounts. 


\section{Conclusions}

Lead-free piezoelectric ceramics $(1-x-y) \mathrm{BNT}-x \mathrm{BKT}-$ $y \mathrm{BM}$, a new member of the BNT-based group, has been successfully synthesized by a conventional ceramics technique. XRD result reveals that $\mathrm{K}^{+}, \mathrm{Bi}^{3+}$ and $\mathrm{Mn}^{3+}$ diffuse into the BNT lattices to form a solid solution with a pure perovskite structure when $x \leq 0 \cdot 21$, and an impurity was observed for a sample with $x=0 \cdot 24$. Addition of $\mathrm{BiMnO}_{3}$ promotes grain growth and addition of BKT suppresses grain growth. Temperature dependences of dielectric properties show that low-temperature hump in dielectric constant curves disappeared slowly with increasing $y$ and appeared again with increasing $x$ and the ceramics are relaxor ferroelectrics. Piezoelectric properties of ceramics increase obviously with increasing content of BKT and $\mathrm{BiMnO}_{3}$ and then decrease, reaching maximum values of $d_{33}=182 \mathrm{pC} / \mathrm{N}$ at $x$ $=0.21(y=0.01)$, and $k_{\mathrm{p}}=0.333$ at $x=0.18(y=0.01)$, respectively.

\section{Acknowledgements}

This work was supported by the National Nature Science Foundation of China (61261012), Guangxi Science Foundation (2010GXNSFD013007 and 2010GXNSFB013010) and Guangxi Education Department Foundation (201012MS083).

\section{References}

Bokov V A, Grigoryan N A, Bryzhina M F and Kazaryan V S 1969 Bull. Acad. Sci. USSR, Phys. Ser. (Engl. Transl.) 331082

Chu B J, Chen D R and Li G R 2002 J. Eur. Ceram. Soc. 222115

Cross L E 1987 Ferroelectrics 76241

Du H L, Zhou W C, Luo F, Zhou D M, Qu S B, Li Y and Pei Z B 2008 J. Appl. Phys. 104034104

Elkechai O, Manier M and Mercurio J P 1996 Phys. Stat. Sol. 157 499

Fedulov S A, Veneutsev Y, Zhdanov G A, Smazheuskaya E G and Rez I S 1962 Sov. Phys. Crystallogr. 762
Ishii H, Nagata H and Takenaka T 2001 Jpn. J. Appl. Phys. 405660 Jaeger R E and Egerton L 1962 J. Am. Ceram. Soc. 45209

Jaffe B, Cook W R and Jaffe H 1971 Piezoelectric ceramics (New York: Academic Press) 135

Jarupoom P, Pengpat K, Pisitpipathsi N, Eitssayeam S, Inatha U, Rujijanagul G and Tunkasiri T 2008 Curr. Appl. Phys. 8253

Lee J K, Yi J Y and Hong K S 2004 J. Appl. Phys. 961174

Li H D, Feng D C and Yao W L 2004 Mater. Lett. 581194

Li Y M, Chen W and Zhou J 2005 Ceram. Int. 31139

Li J F, Wang K, Zhang B P and Zhang L M 2006 J. Am. Ceram. Soc. 89706

Nagata H and Takenaka T 1997 Jpn. J. Appl. Phys. 366055

Nagata H and Takenaka T 1998 Jpn. J. Appl. Phys. 375311

Randall C A and Bhalla A S 1990 Jpn. J. Appl. Phys. 29327

Randall C A, Markgraf S A, Bhalla A S and Baba-Kishi K 1989 Phys. Rev. B40 413

Randall C A, Kim N, Kucera J-P, Cao W and Shrout T R 1998 J. Am. Ceram. Soc. 81677

Saito Y, Takao H, Tani T, Nonoyama T, Takatori K, Homma T, Nagaya T and Nakamura M 2004 Nature 43284

Sawada T, Ando A, Sakabe Y and Damjanovic D 2003 Jpn. J. Appl. Phys. 426094

Shannon R D 1976 Acta Crystallogr. A32 751

Smolenskii G A and Agranovskaya A I 1958 Sov. Phys. Tech. Phys. 31380

Smolenski G A and Aganovskaya A I 1960 Sov. Phys. Solid State 1 1429

Suzuki M, Nagata H and Ohara J 2003 Jpn. J. Appl. Phys. 426090

Wang R, Xie R, Sekiya T, Shimojo Y, Akimune Y, Hirosaki N and Itoh M 2002 Jpn. J. Appl. Phys. 417119

Wang X X, Chan H L W and Choy C L 2003 J. Am. Ceram. Soc. 86 1809

Wang X X, Tang X G and Chan H L W 2004 Appl. Phys. Lett. 8591

Wu J G, Xiao D Q, Wang Y Y, Zhu J G and Yu P 2008 J. Appl. Phys. 103024102

Xu Q, Chen M, Chen W, Liu H X, Kim B H and Ahn B K 2008 Acta Mater. 56642

Yang Z P, Liu B, Wei L L and Hou Y T 2008 Mater. Res. Bull. 4381

Yasuda N and Konda J 1993 Appl. Phys. Lett. 62535

Zhang Q M, Pan W Y, Jang S-J and Cross L E 1988 J. Appl. Phys. 646445

Zhang S J, Shrout T R, Nagata H, Hiruma Y and Takenaka T 2007 IEEE Trans. Ultrasonic Ferroelect. 54910

Zhou C R and Liu X Y 2008 Mater. Chem. Phys. 108413 